\title{
Seedlings Growth assessment of Acacia Polycantha as affected by Soil Media and Seed Origin
}

\author{
Abdalla Nour Eldeen Abdalla ${ }^{1}$, Heba A. Noureldeen ${ }^{1}$, Ahmed Ainuddin Nuruddin ${ }^{2}$ \\ \& Hamdon A Abdelrhman ${ }^{1,2}$, \\ ${ }^{1}$ Department of Soils and Water Sciences, Faculty of NATRES, University of Kordofan, \\ P.O.Box 160, Elobeid, Sudan \\ ${ }^{1}$ Department of Forestry and Range Sciences, Faculty of NATRES, University of Kordofan, \\ P.O.Box 160, Elobeid, Sudan \\ ${ }^{2}$ Dept. Of Techno Economic in Biocomposite Institute of Tropical Forestry and Forest Products, \\ Universiti Putra Malaysia (UPM), 43400, Serdang, Selangor, Malaysia
}

\begin{abstract}
The 2015 International Conference of ERPUB is a worldwide, multidisciplinary academic conference concerned with research, education and application into all aspects of Artificial Intelligence \& Manufacturing Engineering, etc. (Use "abstract" St The aim of this work is assess the seedlings growth performance of Acacia Polycantha as affected by soil media and seeds origin. The study showed that there were significant differences between soils media in the measured parametersin the nursery.The seedlings length in the mixture was better than the sand. Little difference was observed between seedling length in the mixture and clay soil. For the soil media, the investigations illustrated that, most of the growth parameters were improved when grown in mixture soil media. In addition, for the seeds origin, the Blue Nile seedlings length was higher than those of South Kordofan by a difference of $4.1 \mathrm{~cm}$. Likewise a significant difference was obtained between the seedlings root length of the two locations; here the South Kordofan seedlings developed longer root lengths by a difference of $3.4 \mathrm{~cm}$ on average. The shoot/root length ratios of the seedlings of the two locations were 1.8 and 1.4 for Blue Nile and South Kordofan, respectively.
\end{abstract}

Keywords: growth performance; Acacia Polycantha; soil media; seeds origin \& growth parameters.

\section{Introduction}

The demand for greenery and beautification is increasing over all the world in accordance with the development of urban and suburban areas [1]. This demands will lead to huge quantity of diversified quality planting materials, growing medium and plant containers [2]. Moreover with the introduction of indoor and miniature gardens, different types of containers are essential for the proper growth of the plants [3]. Root restriction is an inherent problem with container grown trees, According to [4] (Appleton \& Whitcomb, 1983) plants grown in standard plastic containers for too long often have deformed roots that are kinked or grow along the sides or bottom of the root ball. Results from literature of [5] revealed that tree seedlings raised in poly bags were taller than those from root trainers; probably because many of the poly bags grown seedlings had rooted in the nursery soil and so they were accessing additional resources not available to the root trainer-grown seedlings.in addition, [6] stated that nursery containers have been testified as one of the crucial factors that enhance the successful growth of tree seedlings. Although this provided additional resources to seedlings in bags, it also resulted in severing of roots during transplanting to the field. This greater transplanting stress to the poly bags-grown seedlings compared to the root trainer-grown seedlings could adversely affect their transplant survival and growth.A. polycantha was a tree with multipurpose and can be used for producing Gum Arabic for local villagers to increase their income; fruits of the tree are edible by animals. The species has been overexploited because it is a resource of multiple uses. Moreover, natural regeneration through seeds is very poor due to the insects, cattle and rodents [7]. The main purpose of this work is assess seedlings growth performance of Acacia Polycantha as affected by soil media and seed origin. 


\section{Material and Methods}

Seeds of Acacia polyantha were collected from two regions are: Southern Kordofan, Blue Nile. Soils as nursery potting fills constituted of a sandy soil brought from a stabilized dune sand and a clay soil from Elain Basin. These two soil types were mixed together to make a third growing medium. Containers for nursery stock of black polythene tubes with dimensions of $20 \times 30 \mathrm{~cm}$, were used for seed pretreatment an analytical grade sulfuric acid with concentrations of $25 \%$ and $50 \%$ was acquired from the Laboratory of Gum Arabic Research Center; also a device of electrical needle scratcher was used for this purpose. A polycantha seeds from the two locations were pretreated by the following methods adopt in the work conducted by [7].

\subsection{Nursery stock raising and monitoring of A. polycantha seedlings}

Three treated and untreated seeds were sown directly in the growing media at a depth of three centimeters and lightly covered by fine sand. Watering was applied daily for the first two months by overhead spreading by a container equipped with douche. Nursery operations (weeding, singling, root cutting) were carried out as routinely done. Growth and development of the seedlings were assessed for four months (the reading was recorded every two weeks). Parameters measured were: 1) seedling shoot length (cm); 2) number of leaves; 3) seedling root length $(\mathrm{cm})$; 4) seedling weight (g) (fresh and dry weights of shoot and root); 5) seedling diameter at root collar $(\mathrm{cm}) ; 6$ ) general features of the seedlings growth status, including color, infections and diseases.

\subsection{Data Analysis}

Growth and development of the seedlings were assessed for four months statistically analyzed by SAS in a PC computer used (ANOVA) table and means were separated by Duncan Multiple Range Test and results were obtained in tabulated forms.

\section{Results And Discussions}

\subsection{Seedlings growth assessment of $\mathbf{A}$. polycantha in different growing media}

The following results pertain to the last readings of seedlings growth parameters which were taken after four months from the sowing date in nursery; the measured parameters were seedling length, root length, shoot length/root length ratio, mid diameter, number of leaves, shoot weight, root weight, and shoot weight/root weight ratio.

For the seedling length growth in the various media experimented, seedlings length grown in the sand showed a significant difference $(\mathrm{p} \leqslant 0.05)$ from those raised in the clay and mixture; while seedlings lengths in the clay and mixture media were not significant between them (Table 1 . The highest length was recorded for the mixture $(42.8 \mathrm{~cm})$ and the lowest value was recorded for the sand $(34.1 \mathrm{~cm})$. There was little difference between seedlings lengths in the mixture and the clay media, but the difference between mixture and sand reached to about 1.3 folds.

For the root length, seedlings grown in the sand showed significant difference from those produced in the clay and mixture; while there was no significant difference between the two latter media. Seedlings in the sand medium gave the highest average root length $(32.1 \mathrm{~cm})$, and seedlings length in the clay and mixture were very close to each other. The difference of seedlings lengths between sand and the other media amounted to about 1.5 folds. The shoot/root length ratio between these seedlings stock followed the same trend as out lined above, i.e., there was a significant difference between sand seedlings and those of clay and mixture, but no significant difference between clay and mixture. The ratio in the sand was the lowest, while in the clay and mixture the ratios were almost identical.

For the diameter at root collar, there was no significant difference $(p \leqslant 0.05)$ between the seedlings in the growing media. However, seedlings in the sand gave the highest value of mid-diameter followed by those in clay and mixture media. The difference in values of this parameter between sand and clay exceeded 1.3 folds and between sand and mixture exceeded 1.6 folds. 
For the number of leaves, there was a significant difference between seedlings raised in the mixture and the other two media. Seedlings of the mixture had denser foliage than those of clay and sand media. For the shoot dry weight, a significant difference was recorded between seedlings of mixture and sand media, while there was no difference between both mixture and clay, and clay and sand. Seedlings in the sand had the lowest shoot mass, and seedlings masses in mixture and clay media were almost alike. For the root mass, there was a significant difference between seedlings of sand and the other media. Root mass of sand seedlings was twice greater than that of clay and mixture media. Also, for the shoot/root weight ratio, seedlings of sand medium were significantly different from the respective ratios of seedlings of the other media. While, ratios of seedlings of clay and mixture media did not differ significantly. The weight ratio of seedlings in the sand was far greater lower than that of seedlings of clay and mixture media; this difference exceeded 3.7 folds. On the other hand, shoot/root weight ratio of seedlings of clay and mixture media were identical. The study which conducted by [5] illustrated that, the polybag size has main effects on performance of tree seedlings propagation in the nurseries.

TABLE I. Seedlings growth assessment of A. polycantha in different growing media

\begin{tabular}{lllllllll}
\hline $\begin{array}{l}\text { Growing } \\
\text { media }\end{array}$ & $\begin{array}{l}\text { Seedling } \\
\text { length } / \mathrm{Cm}\end{array}$ & $\begin{array}{l}\text { Number of } \\
\text { leave }\end{array}$ & $\begin{array}{l}\text { Number of } \\
\text { leaflets }\end{array}$ & $\begin{array}{l}\text { Shoot } \\
\text { weight } / g m\end{array}$ & $\begin{array}{l}\text { Mid } \\
\text { diameter } / \mathrm{Cm}\end{array}$ & $\begin{array}{l}\text { Root } \\
\text { weight/gm }\end{array}$ & $\begin{array}{l}\text { Root } \\
\text { length/Cm }\end{array}$ & $\begin{array}{l}\text { Shoot Root } \\
\text { ratio }\end{array}$ \\
\hline Clay & $39.9 \mathrm{a}$ & $16.9 \mathrm{ab}$ & $3355 \mathrm{a}$ & $2.2 \mathrm{ab}$ & $3.3 \mathrm{a}$ & $1.0 \mathrm{~b}$ & $21.3 \mathrm{c}$ & $2.4 \mathrm{a}$ \\
Sand & $34.1 \mathrm{~b}$ & $15.1 \mathrm{~b}$ & $2220 \mathrm{a}$ & $1.4 \mathrm{~b}$ & $4.4 \mathrm{a}$ & $2.215 \mathrm{a}$ & $32.1 \mathrm{a}$ & $0.6 \mathrm{~b}$ \\
Mixture & $42.8 \mathrm{a}$ & $18.0 \mathrm{a}$ & $3233 \mathrm{a}$ & $2.8 \mathrm{a}$ & $2.8 \mathrm{a}$ & $1.306 \mathrm{~b}$ & $23.5 \mathrm{bc}$ & $2.1 \mathrm{a}$ \\
\hline
\end{tabular}

\section{Conclusion}

Finally, the investigation concluded that, the following combinations are proposed for optimum tree seedling growth in nursery for A. polycantha: sand-clay mixture in plastic pots. Moreover, in view of the importance of A. polycantha as potential gum producing tree and render of multipurpose products and services, it is recommend the species to undergo in further research work, particularly:

$1 /$ To investigate thoroughly the natural distribution and the physical requirements of the species, and explore prospects for bringing the species under some management prescriptions naturally.

2/ To intensify field trials and Silviculture work about the species in order to command its establishment and bring it under domestication in the future.

\section{Acknowledgements}

Authors would like to thanks the staff of Ministry of Agriculture North Kordofan State for their technical helps. Also the authors extend their gratitude to the staff of Gum Arabic Research Centre for their contribution in overcoming several problems faced by conducting the research.

\section{References}

[1] Abdelrhman, H. A., Noureldeen, H. A., Ahmed, D. M., \& Shahwahid, M. Effects of Soil Media and Seed Origin on Germination Rate and Seedling Propagation of Acacia polycantha (Wild) subsp. campylacantha (Hochst. ex A. Rich.) Brenan.

[2] Aghai, M. M., Pinto, J. R., \& Davis, A. S. (2014). Container volume and growing density influence western larch (Larix occidentalis Nutt.) seedling development during nursery culture and establishment. New forests, 45(2), 199-213. https://doi.org/10.1007/s11056-013-9402-8

[3] Akpo, E., Stomph, T. J., Kossou, D. K., Omore, A. O., \& Struik, P. C. (2014). Effects of nursery management practices on morphological quality attributes of tree seedlings at planting: The case of oil palm (Elaeis guineensis Jacq.). Forest Ecology and Management, 324, 28-36 https://doi.org/10.1016/j.foreco.2014.03.045

[4] Appleton, B. L., \& Whitcomb, C. E. (1983). Effects of container size and transplanting date on the growth of tree seedlings. J. Environ. Hort, 1(4), 89-93. 
[5] Missanjo, E., Chioza, A., \& Kulapani, C. (2014). Effects of Different Pretreatments to the Seed on Seedling Emergence and Growth of Acacia polyacantha. International Journal of Forestry Research, 2014.

https://doi.org/10.1155/2014/583069

[6] Poorter, H., Fiorani, F., Stitt, M., Schurr, U., Finck, A., Gibon, Y., . . . Tardieu, F. (2012). The art of growing plants for experimental purposes: a practical guide for the plant biologist. Functional Plant Biology, 39(11), 821-838. https://doi.org/10.1071/FP12028

[7] Sharif, N., Ishfaq, M., Memon, N., \& Riaz, S. (2014). Standardization of potting media for nursery raising seedlings of jujube (Zyzyphus mauritiana Lamk.). Journal of Agricultural Technology, 10(5), 1231-1239.

[8] Yajie, X. (2015). Assessment of the Importance of Greenery in Urban Planning in Modern Britain. Journal of Landscape Research, 7(3), 1. 